\title{
MODELING OF THE INTERLAMELLAR SPACING OF ISOTHERMALLY FORMED PEARLITE IN AN EUTECTOID STEEL
}

\author{
F.G. Caballero ${ }^{1,2}$, C. Capdevila ${ }^{1,2}$ and C. García de Andrés ${ }^{1}$, \\ ${ }^{1}$ Department of Physical Metallurgy \\ Centro Nacional de Investigaciones Metalúrgicas (CENIM) \\ Consejo Superior de Investigaciones Científicas (CSIC) \\ Avda. Gregorio del Amo, 8. 28040 Madrid, Spain \\ ${ }^{2}$ Department of Materials Science and Metallurgy \\ University of Cambridge \\ Pembroke Street, Cambridge CB2 3QZ, UK
}

Keywords: eutectoid steels, phase transformations, modeling

\section{$\underline{\text { Introduction }}$}

Pearlite is a lamellar product of eutectoid decomposition, which may form in steels and non-ferrous alloys during transformations under isothermal or continuous-cooling $(1,2)$. A pearlite nodule is composed of multiple colonies; each colony has parallel lamellae, which are orientated differently with respect to lamellae in adjacent colonies. This also exhibits a wide range of interlamellar spacings in different colonies because of the intersection of pearlite colonies at different angles with the polishing plane. The interlamellar spacing is reflected by the diffusion kinetics at the transformation front and is a sensitive parameter which, in a particular steel, is larger as the transformation temperature increases (3). Mehl and co-workers (3) demonstrated that the spacing decreased as the degree of undercooling, $\Delta T$, below the eutectoid temperature, increased. Zener (4) provided the first theoretical analysis of these observations, which allows to calculate the interlamellar spacing of pearlite as a function of undercooling.

Pearlite transformation in steels is reconstructive and known to show a constant growth rate (5). The growth rate of pearlite is believed to be controlled by either volume diffusion of carbon $(4,6)$ or by boundary diffusion of substitutional alloying elements (7).

In the present work, three different morphologies of pearlite were formed isothermally at three temperatures in an eutectoid steel finding out, as Mehl et al. and Zener reported $(3,4)$, that the pearlite is finer as the formation temperature decreases. Moreover, the interlamellar spacings were calculated using the theoretical method proposed by Zener and Hillert (4,6,7). Experimental results suggest that the growth of pearlite is controlled mainly by volume diffusion of carbon in austenite in the temperature range studied in this steel.

\section{Materials and Experimental Procedure}

The chemical composition of the studied steel is presented in Table I. Cylindrical samples of $2 \mathrm{~mm}$ in diameter and $12 \mathrm{~mm}$ in length were austenitized for $5 \mathrm{~min}$ at $1273 \mathrm{~K}$, isothermally transformed at temperatures ranging from 798 to $948 \mathrm{~K}$ for different times and subsequently cooled rapidly to room temperature. Table II lists all the temperatures and holding times used for the isothermal decomposition of austenite in this steel.

Table I.- Composition of eutectoid steel (mass \%)

\begin{tabular}{cccc}
\hline $\mathrm{C}$ & $\mathrm{Si}$ & $\mathrm{Mn}$ & $\mathrm{P}$ \\
\hline 0.76 & 0.24 & 0.91 & 0.013 \\
\hline
\end{tabular}


Specimens were polished using standardized techniques and finished on $0.25 \mu \mathrm{m}$ diamond paste for metallographic examination. An etching solution of picric acid in isopropyl alcohol with several drops of Vilella's reagent was used to disclose the pearlite morphology in specimens MORF1-2 on a JEOL JXA-820 scanning electron microscope (SEM). The morphology of pearlite in specimen MORF3 was revealed by transmission electron microscopy. Cylindrical samples were sliced into $100 \mu \mathrm{m}$ thick discs and subsequently ground down to a thickness of $50 \mu \mathrm{m}$ on wet 800 grit silicon carbide paper. These foils were finally electropolished in a twin-jet electropolishing equipment (E. A. Fischione Inst. Mfg - Model 110) at room temperature and a voltage of $100 \mathrm{~V}$ using a solution of $5 \%$ perchloric acid, $15 \%$ glycerol and $80 \%$ methanol. Thin foils were examined in a JEOL -200CX transmission electron microscope (TEM) at an operating voltage of $200 \mathrm{kV}$.

Table II.- Heat treatment for the isothermal decomposition of austenite

\begin{tabular}{ccc}
\hline Specimen & Temperature, K & Time, min \\
\hline MORF1 & 948 & 45 \\
MORF2 & 923 & 10 \\
MORF3 & 798 & 60 \\
\hline
\end{tabular}

\section{$\underline{\text { Results and Discussion }}$}

Figure 1 shows scanning (MORF1 and MORF2) and transmission (MORF3) electron micrographs of the three morphologies of pearlite studied in this steel.

(a) MORF1. SEM

(b) MORF2. SEM

(c) MORF3. TEM

Figure 1.- Electron micrographs of the three different morphologies of pearlite considered in this study. 

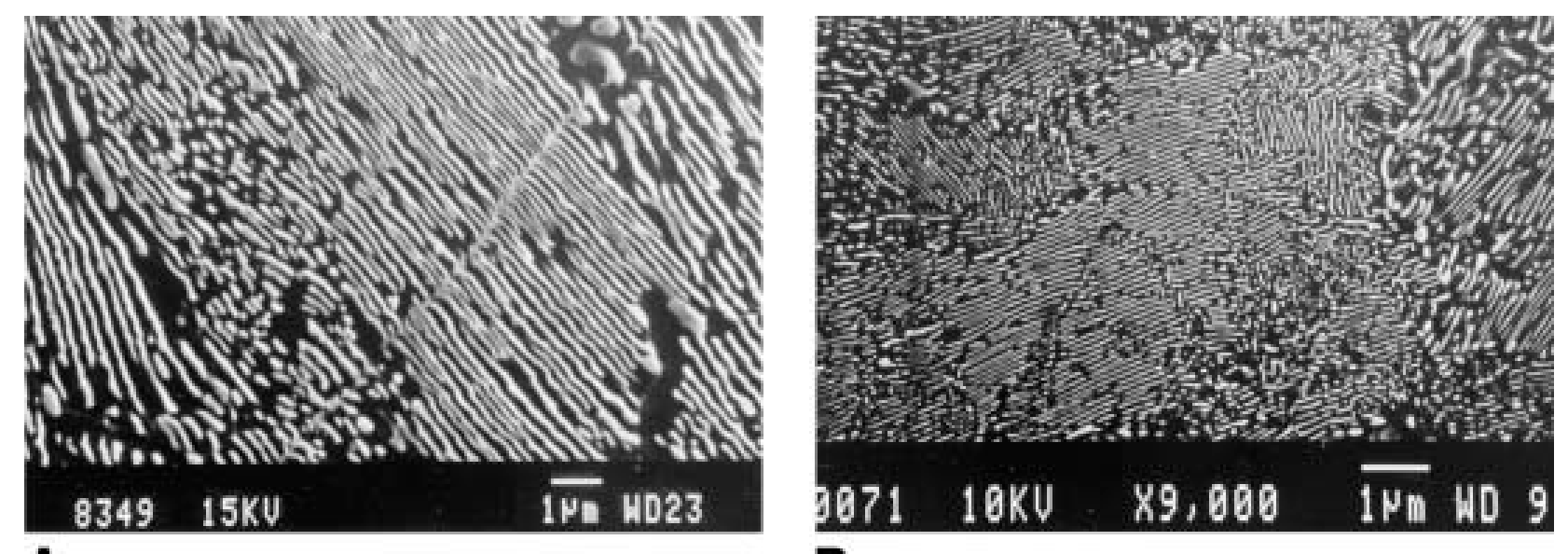

A

\section{B}

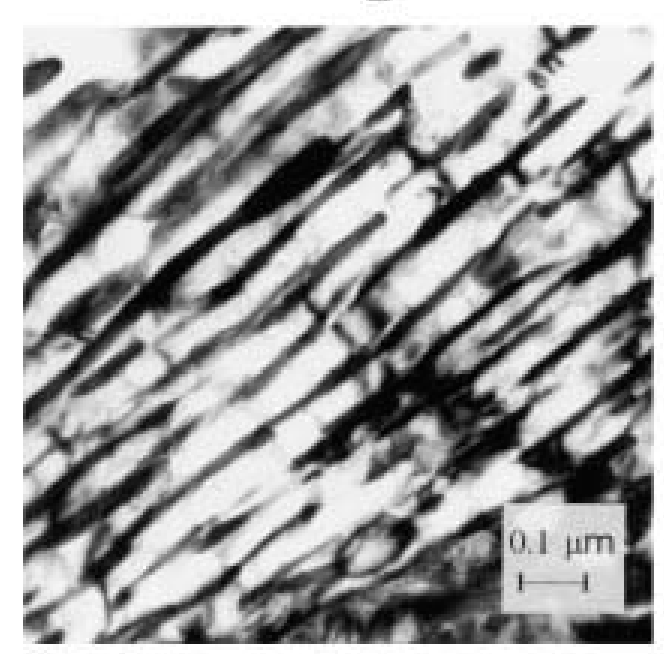

C

Figure 1. Electron micrographs of the three different morphologies of pearlite considered in this study. (a) MORF1.SEM. (b) MORF2.SEM. (c) MORF3.SEM. 
The average true interlamellar spacing $\left(\sigma_{o}\right)$ was obtained from electron micrographs according to Underwood's intersection procedure (8). The data for $\sigma_{o}$ are shown in Table III.

In agreement with Mehl and co-workers (3), experimental interlamellar spacing values in Table III decrease as the formation temperature decreases reaching a minimum value of $0.06 \mu \mathrm{m}$ approximately.

The growth rate of pearlite is believed to be controlled by either volume diffusion of carbon $(4,6)$ or by boundary diffusion of substitutional alloying elements (7). When the growth rate of pearlite is controlled by the bulk diffusion of atoms in austenite ahead of the interface, the diffusion of carbon may play a more important role than that of substitutional alloying elements, since the diffusivity of the substitutional alloying elements in austenite is far smaller than that of carbon. As a result, the substitutional alloying elements may not diffuse a long distance during the reaction. The growth rate of pearlite, in that case, is expressed as follows (6):

$G_{v}=K_{v} \frac{1}{\sigma_{o}}\left(1-\frac{\sigma_{c}}{\sigma_{o}}\right)$

where $G_{v}$ is the volume diffusion controlled growth rate of pearlite, $K_{v}$ is constant at a given temperature, $\sigma_{o}$ is the interlamellar spacing and $\sigma_{c}$ is the theoretical critical spacing at zero growth rate.

Since Eq. [1] contains two unknown parameters, $G_{v}$ and $\sigma_{o}$, for a given temperature $T$, it does not provide a unique solution. However, Zener (4) proposed that the value of the interlamellar spacing of pearlite, $\sigma_{o}$, should satisfy the maximum growth rate criterion. Therefore, the following relationship between $\sigma_{o}$ and $\sigma_{c}$ is obtained by setting the first derivative of Eq. [1] equal to zero:

$\sigma_{o}=2 \sigma_{c}$

with

$\sigma_{c}=\frac{2 T_{e} \sigma_{\alpha \theta}}{\rho Q\left(T_{e}-T\right)}$

where $T_{e}$ is the eutectoid temperature, $\sigma_{\alpha \theta}$ is the interfacial energy per unit area of the ferrite-cementite lamellar boundary in pearlite, $\rho$ is the density, $Q$ is the heat of transformation per unit mass. Combining Eqs. [2] and [3] gives an expression for $\sigma_{o}$ based on Zener's hypothesis:

$\sigma_{o}=\frac{4 T_{e} \sigma_{\alpha \theta}}{\rho Q\left(T_{e}-T\right)}$

Table III.- Morphological characterization of pearlite

\begin{tabular}{ccc}
\hline Specimen & Temperature,K & $\sigma_{o}, \mu \mathrm{m}$ \\
\hline MORF1 & 948 & $0.20 \pm 0.03$ \\
MORF2 & 923 & $0.08 \pm 0.01$ \\
MORF3 & 798 & $0.06 \pm 0.01$ \\
\hline
\end{tabular}

On the other hand, Takahashi (9) provided an empirical expression for the interlamellar spacing as a function of the temperature and the alloying content as written:

$\log \left(\sigma_{o}\right)=-2.2358+0.0986 M n-0.0543 C r+0.0337 N i-\log \left(\frac{T_{e}-T}{T_{e}}\right)$ 
where $\sigma_{o}$ is given in $\mu \mathrm{m}$ and $\mathrm{Mn}, \mathrm{Cr}$ and $\mathrm{Ni}$ in wt-\%.

Comparing Eqs. [4] and [5] the following relation should be considerate:

$\log \left(\frac{4 \sigma_{\alpha \theta}}{\rho Q}\right)=-2.2358+0.0986 \mathrm{Mn}-0.0543 \mathrm{Cr}+0.0337 \mathrm{Ni}$

Substituting the alloying content of the steel in Eq. [6] and considering an approximated eutectoid temperature, $T_{e}$, of $1000 \mathrm{~K}, \mathrm{Eq}$. [4] could be rewritten as follows:

$\sigma_{o}=\frac{7.1437}{(1000-T)}$ in $\mu \mathrm{m}$

When the partitioning of the substitutional alloying elements is substantial during the growth of pearlite, boundary diffusion of the alloying elements may control the growth rate of pearlite. In that case, the growth rate is expressed below (7):

$G_{b}=K_{b} \frac{1}{\sigma_{o}^{2}}\left(1-\frac{\sigma_{c}}{\sigma_{o}}\right)$

where $G_{b}$ is the boundary diffusion controlled growth rate and $K_{b}$ is a constant at a given temperature. For boundary diffusion controlled growth, the maximum growth rate criterion gives:

$\sigma_{o}=\frac{3}{2} \sigma_{c}=\frac{3 T_{e} \sigma_{\alpha \theta}}{\rho Q\left(T_{e}-T\right)}$

Substituting Eq. [9] in Takahashi's expression and following the above mathematical procedure, an expression of the interlamellar spacing as a function of temperature is obtained in this steel for the case of boundary diffusion controlled pearlite growth:

$\sigma_{o}=\frac{2.6789}{(1000-T)}$ in $\mu \mathrm{m}$

Figure 2 represents the variation of the interlamellar spacing as a function of undercooling for a volume and boundary diffusion controlled pearlite growth calculated according to Eqs. [7] and [10], respectively. Moreover, this figure shows the experimental values of interlamellar spacing listed in Table III.

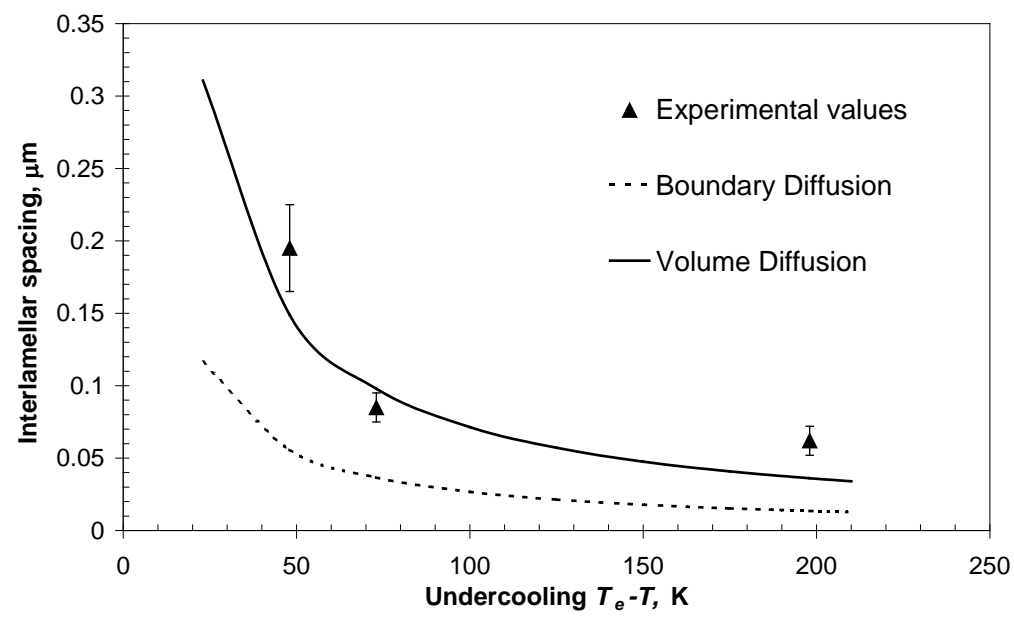

Figure 2.- Variation of Interlamellar spacing as a function of undercooling. 
Figure 2 suggests that the growth of pearlite is controlled mainly by volume diffusion of carbon in austenite in the temperature range studied in this steel. Experimental results seem to follow a tendency similar to that of the volume diffusion curve rather than that for a boundary diffusion controlled growth.

\section{Conclusions}

1. Three different morphologies of pearlite were formed isothermally at three temperatures in eutectoid steel (0.76C-0.91Mn-0.24Si-0.013P). The interlamellar spacings of these morphologies were measured by electron microscopy finding out that the pearlite is finer the lower the transformation temperature, reaching a minimum value of $0.06 \mu \mathrm{m}$ approximately.

2. A theoretical model to calculate the interlamellar spacing of pearlite as a function of the undercooling has been proposed in this work by means of the theories of Zener and Hillert, and Takahashi's empirical formulae.

3. This model has been experimentally validated at three different temperatures in this steel. A good agreement between experimental and calculated values of the interlamellar spacings has been found when the growth of pearlite is considered to be controlled by the diffusion of carbon in the austenite in the studied temperature range.

\section{Acknowledgements}

The authors acknowledge financial support from the European Coal and Steel Community (ECSC-7210. EC/939) and the Spanish Comisión Interministerial de Ciencia y Tecnología (CICYT-MAT95-1192-CE)

\section{References}

1. N. Ridley, Metall. Trans., vol. 16A, 1019 (1984).

2. N. Ridley, in Proceedings of the International Conference on Phase Transformations in Ferrous Alloys (A.R. Marder and J.I. Goldstein, Eds.), TMS-AIME, Warrendale, Pa., 201 (1984).

3. R.F. Mehl, C.S. Barrett and D.W. Smith, Trans. AIME, 105, 215 (1933)

4. C. Zener, Trans. AIME, 167, 550 (1946).

5. J.W. Christian, 'The Theory of Transformations in Metals and Alloys. Part 1', Pergamon Press, Oxford, (1975).

6. M. Hillert, Jernkont. Ann., 141, 757 (1957).

7. M. Hillert, 'The Mechanism of Phase Transformation in Crystalline Solids', Institute of Metals, London, 231 (1969).

8. E.E. Underwood, 'Quantitative Stereology’, Addison-Wesley Reading, Massachusetts, (1970).

9. M. Takahashi, 'Reaustenitization from Bainite in Steels', Disertation submitted for the degree of Doctor of Philosophy, at the University of Cambridge, 132 (1992). 